\title{
What do Australian adults eat for breakfast? A latent variable mixture modelling approach for understanding combinations of foods at eating occasions
}

\author{
Rebecca M. Leech ${ }^{1 *}$, Carol J. Boushey ${ }^{2}$ and Sarah A. McNaughton ${ }^{1}$
}

\begin{abstract}
Background: The patterning of food intake at eating occasions is a poorly understood, albeit important, step towards achieving a healthy dietary pattern. However, to capture the many permutations of food combinations at eating occasions, novel analytic approaches are required. We applied a latent variable mixture modelling (LVMM) approach to understand how foods are consumed in relation to each other at breakfast.

Methods: Dietary intake at breakfast ( $n=8145$ occasions) was assessed via 24-h recall during the 2011-12 Australian National Nutrition and Physical Activity Survey $(n=3545$ men and $n=4127$ women, $\geqslant 19$ y). LVMM was used to determine breakfast food profiles based on 35 food group variables, reflecting compliance with Australian Dietary Guidelines. F and adjusted-chi2 tests assessed differences in timing of consumption and participant characteristics between the breakfast profiles. Regression models, adjusted for covariates, were used to examine associations between breakfast food profiles and objective adiposity measures (BMI and waist circumference).

Results: Five distinct profiles were found. Three were similar for men and women. These were labelled: "Wholegrain cereals and milks" (men: 16\%, women: 17\%), "Protein-foods" (men and women: 11\%) and "Mixed cereals and milks" (men: 33\%, women: 37\%). Two "Breads and spreads" profiles were also found that were differentiated by their accompanying beverages (men) or type of grain (women). Profiles were found to vary by timing of consumption, participant characteristics and adiposity indicators. For example, the "Protein-foods" profile occurred more frequently on weekends and after $9 \mathrm{am}$. Men with a "Bread and spreads (plus tea/coffee)" profile were older $(P<$ $0.001)$ and had lower income and education levels $(P<0.05)$, when compared to the other profiles. Women with a "Protein-foods" profile were younger $(P<0.001)$ and less likely to be married $(P<0.01)$. Both men and women with a "Wholegrain cereals and milks" profile had the most favourable adiposity estimates $(P<0.05)$.

Conclusions: We identified five breakfast food profiles in adults that varied by timing of consumption, participant characteristics and adiposity indicators. LVMM was a useful approach for capturing the complexity of food combinations at breakfast. Future research could collect contextual information about eating occasions to understand the complex factors that influence food choices.
\end{abstract}

Keywords: Eating patterns, Dietary patterns, Eating occasions, Breakfast, 24-h recall

\footnotetext{
*Correspondence: rebecca.leech@deakin.edu.au

${ }^{1}$ Institute for Physical Activity and Nutrition (IPAN), School of Exercise and Nutrition Sciences, Deakin University, Geelong, Victoria, Australia

Full list of author information is available at the end of the article
}

(C) The Author(s). 2021 Open Access This article is licensed under a Creative Commons Attribution 4.0 International License, which permits use, sharing, adaptation, distribution and reproduction in any medium or format, as long as you give appropriate credit to the original author(s) and the source, provide a link to the Creative Commons licence, and indicate if changes were made. The images or other third party material in this article are included in the article's Creative Commons licence, unless indicated otherwise in a credit line to the material. If material is not included in the article's Creative Commons licence and your intended use is not permitted by statutory regulation or exceeds the permitted use, you will need to obtain permission directly from the copyright holder. To view a copy of this licence, visit http://creativecommons.org/licenses/by/4.0/. The Creative Commons Public Domain Dedication waiver (http://creativecommons.org/publicdomain/zero/1.0/) applies to the data made available in this article, unless otherwise stated in a credit line to the data. 


\section{Introduction}

A poor quality diet is a major modifiable contributor to obesity and its long-term effects, including chronic disease death and disability, globally [1]. Current dietary guidelines around the world utilise a food-based framework to promote the adoption of healthy dietary patterns [2-4]. The emphasis by dietary guidelines on foods that make up the whole diet, rather than on individual nutrients, reflects the increasing body of evidence that has accrued over recent decades in relation to the health effects of specific food groups and dietary patterns $[5,6]$. Nutrition guidance based on foods is also more relevant because people select foods, rather than nutrients, and overall diet quality is thus driven by the quality of food components.

However, individuals rarely consume foods in isolation. Instead, they select combinations of foods at eating occasions, including meals and snacks. The patterning of food intake at eating occasions, or eating patterns, are an integral, yet poorly understood, intermediary step to achieving a healthy dietary pattern and preventing obesity and its complications [7]. Eating patterns incorporate aspects of timing, frequency, regularity, as well as, the food and nutrient composition of eating occasions [8]. There is growing recognition and research to suggest that aspects of eating patterns play an important role in weight management and health [7, 9]. Furthermore, an understanding of eating patterns can inform the development and translation of dietary guidelines by helping to contextualise advice and provide practical guidance on what foods should be consumed more often, in which combinations and at which times $[10,11]$.

A key aspect of eating patterns is the composition of eating occasions, particularly the combination of foods [7]. The breakfast eating occasion has long been marketed as "the most important meal of the day" [12] and evidence suggests that regularly eating breakfast promotes better overall diet quality [7, 9] and, possibly, more favourable cardiometabolic risk factors including obesity $[9,13]$. For example, there is some evidence that regular consumption of ready-to-eat breakfast cereals may protect against weight gain, although the effects of different breakfasts, including cereal types remains unclear $[14,15]$. Research that provides a detailed examination of food combinations at eating occasions in relation to obesity and health outcomes is needed to elucidate meal-specific diet-disease associations. Further, dietary guidance for what to consume at breakfast and other eating occasions are usually provided as a list of food groups or components to include or limit but does not specify the possible ways foods may be selected and combined to optimise diet quality. Eating patterns may be influenced by national and cultural norms [16]; and dietary guidance that integrates nationally and culturally relevant food practices may also assist populations to follow a healthy eating pattern.

Relatively little research has examined how people select and combine foods at eating occasions, [7], including at breakfast [17-19]. One reason for this is the analysis of eating occasions is challenging due to the skewed and semi-continuous nature of the food intake data. This is explained by recognizing that an eating occasion is a snapshot of time during which a relatively small number of foods are selected for consumption from a larger array of food choices resulting in many possible food combinations and the possibility of a high proportion of non-consumption for a given food subgroup at each eating occasion. Few approaches to overcome these data challenges have been explored; these include data mining techniques [17, 18] and semiparametric Gaussian Copula Graphical models [19]. While these exploratory approaches aid understanding of complex interrelationships between dietary variables from multi-dimensional data, they do not characterize individuals on the basis of their dietary behaviours by either designation of a dietary score or group membership (i.e., dietary patterns analysis) [20]. Further exploration of alternative approaches that are accessible and feasible for understanding how individuals consume foods in relation to each other at eating occasions will help disentangle the patterns of consumption at eating occasions and opportunities for achieving a healthy eating pattern.

Cluster analysis, and more recently latent class analysis, are two established exploratory statistical approaches that can be useful for understanding the patterning of behaviours [21-23], including dietary patterns $[6,20,24,25]$ and temporal eating patterns [26, 27]. Since the approaches are data-driven and personcentred, they can be used to identify different groups of people who share similar patterns of behaviour. An advantage of LCA over cluster analysis is the derived groups (referred to as clusters, classes or profiles) are based on probabilistic mixture modelling which helps to minimise the subjectivity regarding the selection of final group numbers and can be extended to handle complex data (e.g., binary, categorical, ordinal, continuous variables with standard and non-standard distributions and skewness) [28]. Therefore, we applied a latent variable mixture modelling (LVMM) approach (an extension of LCA) to examine profiles of food combinations at breakfast eating occasions in a large and nationally representative sample of Australian adults. To understand the potential use of LVMM for assessing meal-specific associations with obesity and health outcomes, we also examined the whether the resulting breakfast profiles 
varied by time of consumption and participant characteristics, including adiposity.

\section{Subjects and methods Sample and study design}

This study is a secondary cross-sectional analysis of nationally representative dietary data collected from adult respondents who participated in the Australian National Nutrition and Physical Activity Survey, 2011-2012 (NNPAS 2011-12). The NNPAS, administered by the Australian Bureau of Statistics (ABS), covered approximately $97 \%$ of the population living in urban and rural (excluding very remote) areas of Australia; the survey design and data collection methods have been published in detail previously [29]. In summary, the survey employed a multistage, probability sampling design of usual residents in private dwellings, and included 12,153 persons aged 2 years or over (77\% response rate) of whom 9115 were adults ( $n=4282$ men and $n=4833$ women) aged over 18 years, not currently pregnant or breastfeeding. Person-specific weights, adjusted for probability of selection and non-response, were used to provide estimates relating to the whole population. The Census and Statistics Act 1905 provides ethics approval for the ABS to conduct the household interview components of health surveys [29]. As this study involves the secondary analysis of pre-existing and nonidentifiable data, an exemption from ethics review was approved by the Deakin University Human Research Ethics Committee ([DUHREC]; application 2018-415).

\section{Dietary assessment}

Dietary data were collected during two 24-h recalls using the validated USDA automated multiple 5-pass method [30, 31]. The dietary assessment period covered all four seasons and all days of the week (excluding Sunday, unless requested by the participant) between May 2011 and June 2012. The distribution of recalls across the week were as follows: between 14 and $18 \%$ for weekdays, $11.5 \%$ for Saturdays and 3.5\% for Sundays [29]. The first recall was conducted by trained ABS staff during a household interview and the second was conducted approximately 9 days later during a telephone interview in a subset of 6053 (65\%) of the adult respondents. For the current exploratory analysis of breakfast eating occasions, nationally-representative dietary data from men and women who completed the first recall day were used.

\section{Breakfast eating occasions and food groups}

During the 24-h recall, respondents identified the starting time and type of each eating occasion. A single eating occasion was defined according to the current recommendations as any occasion where a food or beverage was ingested, contained a minimum energy content of $210 \mathrm{~kJ}$ and was separated in time from the preceding and succeeding eating occasions by $15 \mathrm{~min}$ [32]. Eating occasions reported by the participant as breakfast/brunch were coded as breakfast, consistent with recent research examining the nutritional composition of breakfast in US adults [33-35]. As shown in Additional File 1, participants were excluded from the analysis if they were missing data on time of eating $(n=$ 226), did not report a breakfast eating occasion $(n=956)$ or reported a breakfast eating occasion containing fewer than $210 \mathrm{~kJ}(n=196)$.

All foods and beverages reported by participants at breakfast ( $n=8145$ eating occasions; Additional File 1 ) were classified into 35 food groups (described in Additional File 2) to align with the 2013 Australian Dietary Guidelines (ADG) [2]. Food and beverage intakes (g/d) were calculated using the Australian Health Survey ADG database [36] and the AUSNUT 2011-13 food group classification [37], both developed by Food Standards Australia New Zealand for the NNPAS 2011-12. For the ADG Database, the ABS disaggregated and estimated all individual food components within a mixeddish using the AUSNUT 2011-13 recipe file [37].

Using the ADG database [36], intakes (g/d) of 26 food groups consumed by participants at breakfast were calculated. These included 22 groups based on the five food group foods: grains (6 groups), vegetables and legumes (5 groups), fruit (excluding fruit juice; 2 groups), dairy and alternatives ( 4 groups) and meat and alternatives (5 groups). Other ADG groups included unsaturated spreads and oils ( 2 groups), water (1 group) and 100\% fruit juice (1 group). Intake of food groups (g/d) not estimated in the ADG database were calculated based on the AUSNUT 2011-13 (minor and major food codes) food group classification system [37]. These included tea/coffee (one group) and energy-dense nutrient poor 'discretionary' foods (8 groups) [38]. All food group intakes at the breakfast eating occasion were adjusted for breakfast energy intake using the residual method by regressing food group intakes on total energy intake at breakfast $[39,40]$.

\section{Time of consumption}

Using information on the day of the week that the 24-h dietary recall was administered, breakfast occasions were classified as occurring between Monday and Friday (weekday) or on Saturday/Sunday (weekend). Breakfast occasions were further classified according to the following time slots: $<7: 00 \mathrm{~h}, 7: 00-7$ : $59 \mathrm{~h}, 8: 00-8: 59 \mathrm{~h}$ and $\geq 9: 00 \mathrm{~h}$, using information on eating occasion starting time. 


\section{Participant characteristics}

During the household interview, information was also collected about participants' age, gender, country of birth, geographical region of residence, social marital status, highest attained level of education, and household income [29]. Unless indicated otherwise, the variables used for this analysis were defined and categorised by the ABS and included: country of birth (Australia, other 'mainly English speaking' countries, all other countries); geographical region of residence (Major cities of Australia, inner regional cities of Australia, other regions); social marital status (married [in a registered or de facto marriage], not married); smoking status (never smoked, past-smoker, current smoker), and meeting (yes or no) the Australian physical activity guidelines of 150 min and 5 sessions in the previous week [41]. Highest attained level of education was provided by the ABS and further categorised for this analysis as low (completed some high-school or less), medium (completed highschool or completed some high-school and/or certificate/diploma) or high (having a tertiary qualification). Deciles of participants' weekly gross household income (Australian dollars [AUD]) that accounted for the number of persons living in the household were provided by the ABS [29]. For this analysis, deciles were collapsed into quintiles (reference ranges in AUD: quintile 1, $<\$ 398$; quintile 2, \$399-638; quintile 3, \$639-958; quintile $4, \$ 959-1438$ and quintile $5, \geq \$ 1439$ ). Participants reported the number of hours worked in the previous week and were categorised as: $0 \mathrm{~h},<40 \mathrm{~h}$ or $\geq 40 \mathrm{~h}$ per week. Anthropometric measurements (to 1 decimal point) of height $(\mathrm{cm}$; portable stadiometer), weight $(\mathrm{kg}$; digital scales), and waist circumference $(\mathrm{cm}$; metal tape measure) were taken by trained ABS staff during the household interview. Body mass index (BMI) $(\mathrm{kg} / \mathrm{m} 2)$ was calculated.

\section{Statistical analysis \\ Latent profiles of breakfast food combinations}

Two-part latent Variable Mixture Modelling (LVMM) was performed in MPlus Version 8.2 (Muthen \& Muthen, Los Angeles, CA, USA) to identify distinct breakfast food combination profiles for men and women, separately. LVMM is an extension of latent class analysis, a statistical technique that identifies categorical latent class/profile variables on the basis of observed categorical or continuous variables [21, 42]. For this analysis, the data "two-part" option was applied in MPlus as the intake distributions of the 35 food groups at breakfast were semi-continuous (i.e., had a lumping of values at zero and a highly-skewed tail) [43]. The two-part option allows for estimation of both the binary distribution of the variable (i.e. was the food group consumed or not consumed at breakfast) and the continuous distribution of the variable (i.e. mean intake among the food group consumers). Therefore, participants were assigned to the latent profiles on the basis of: 1) consumption of food groups at breakfast (yes/no) and 2) the intake amount of food groups consumed (if consumed). Although a small number of participants $(n=230)$ reported more than one breakfast eating occasion, these participants were included for the identification of food combinations and the "complex mixture" analysis option was specified to allow for the clustering of eating occasions by individuals $[42,43]$. The NNPAS replicate weights were not applied as this option was not available with the complex mixture analysis in MPlus. The final number of latent profiles to extract was determined using model fit indices. These included: the Bayesian information criterion (BIC) and sample size adjusted BIC (lower values indicate a better model fit); the standardised entropy index (value range between zero and one; higher values indicate better class separation), and the Lo-Mendell-Rubin Likelihood Ratio test [LMR-LRT], which compares nested ( $k$ vs. $k-1$ ) latent class models using an approximation of the distribution of difference of the two log likelihoods. A $p$-value $<0.05$ for the LMR-LRT indicates that the more complex model $(\mathrm{k})$ provides a better fit for the data than the simpler model (k-1). The interpretability of the breakfast food profiles was also considered when determining the final latent profile solution (Table 1) [42, 43]. As there may be day-to-day variability in breakfast food profiles (i.e., a breakfast food profile may differ from 1 day to the next), the reliability of the latent profiles was examined by repeating LVMM procedures using data from the second day of dietary recall ( $n=2320$ men and $n=2770$ women).

\section{Associations between latent breakfast profiles, time of consumption and participant characteristics}

All analyses for the associations of the breakfast food profiles with participant characteristics were conducted using Stata 15 (Stata Inc., College Station, TX, USA). The analysis used person weights to derive point estimates relating to the Australian population and replicate weights to adjust standard errors for the clustered survey design [29]. For all analyses, $P<0.05$ was considered statistically significant. The very small proportion $(2.8 \%)$ of participants reporting more than one breakfast eating occasion were excluded from the subsequent analyses of associations with food intakes and participant characteristics which included 3545 men and 4127 women.

Descriptive statistics for food intakes, time of consumption and participant characteristics are presented as weighted means (95\% confidence intervals $[\mathrm{CI}]$ ) or weighted percentages. As some foods were rarely consumed for a given breakfast food profile, the mean intake 
Table 1 Model fit indices for latent profiles of food combinations at breakfast eating occasions ${ }^{a}$

\begin{tabular}{|c|c|c|c|c|c|}
\hline & 2 classes & 3 classes & 4 classes & 5 classes & 6 classes \\
\hline \multicolumn{6}{|l|}{ Men } \\
\hline Loglikelihood & $-60,711.023$ & $-59,309.719$ & $-58,281.212$ & $-57,825.658$ & $-57,424.792$ \\
\hline Entropy & 0.819 & 0.873 & 0.872 & 0.868 & 0.849 \\
\hline $\mathrm{BIC}$ & $122,871.330$ & $120,642.489$ & $119,181.015$ & $118,854.561$ & $118,637.483$ \\
\hline adjusted BIC & $122,312.086$ & $119,857.641$ & $118,170.563$ & $117,618.505$ & $117,175.822$ \\
\hline${ }^{b}$ LMR-LRT & $5586.967, P<0.001$ & $2808.885, P<0.001$ & $2042.776, P<0.001$ & $912.682, P=0.01$ & $794.951, P=0.08$ \\
\hline \multicolumn{6}{|l|}{ Women } \\
\hline Loglikelihood & $-67,230.626$ & $-65,773.386$ & $-64,449.367$ & $-63,598.615$ & $-63,454.789$ \\
\hline Entropy & 0.863 & 0.881 & 0.878 & 0.926 & 0.889 \\
\hline $\mathrm{BIC}$ & $135,936.216$ & $133,617.594$ & $131,564.811$ & $130,458.564$ & $130,766.168$ \\
\hline adjusted BIC & $135,376.959$ & $132,832.727$ & $130,554.335$ & $129,222.479$ & $129,304.474$ \\
\hline bLMR-LRT & $6122.822, P=0.12$ & $2900.629, P<0.0001$ & $2643.024, P<0.0001$ & $1742.887, P<0.0001$ & $336.794, P=0.13$ \\
\hline
\end{tabular}

${ }^{a}$ AIC Akaike Information Criterion, BIC Bayesian Information Criterion, BS Bootstrap, LMR Lo-Mendell-Rubin, LRT likelihood ratio test

${ }^{\mathrm{b}}$ Adjusted Lo-Mendell-Rubin likelihood ratio test for $\mathrm{k}$ versus $\mathrm{k}-1$ profiles. Values are two times the loglikelihood difference and corresponding $p$-value

was only calculated when the proportion of participants consuming the item was $\geq 5 \%$. For continuous variables, the $F$-test was used to determine differences in participant characteristics between latent breakfast food profiles, with Bonferroni correction to account for multiple testing across $>2$ profiles. For categorical variables, differences between latent profiles were assessed using the adjusted Pearson Chi-2 test for survey data. Multiple linear regression (for continuous outcomes) and logistic regression (for binary outcomes) were used to test for associations between breakfast food profiles, and the following measures of adiposity: BMI and waist circumference (WC; continuous) and overweight/obesity and central overweight/obesity status (binary). Models included men and women with no missing data for BMI and WC. All adiposity estimates were adjusted for age (y, continuous), education level (categorical), smoking status (categorical), meeting physical activity guidelines (categorical) and energy intake (kJ, continuous) at all eating occasions excluding breakfast. Pairwise differences, with Bonferroni correction, of adjusted mean adiposity estimates between latent breakfast profiles were calculated.

\section{Results}

\section{Latent profiles of breakfast food combinations}

Model fit indices favoured a five-class model for both men and women (Table 1). The combination of smaller $\mathrm{BIC}$ and adjusted BIC values, entropy values $>0.8$ for and results from the LMR-LRT indicated a five-class solution. The breakfast food profiles for men and women were labelled according to their distinguishing features, indicated by the proportion of participants consuming particular food group items and the corresponding mean intake at the breakfast eating occasion, when compared to the other profiles (Tables 2 and 3). Similar breakfast food profiles were also observed after repeating LVMM procedures on the second day of dietary recall data (Additional Files 3 and 4). Three profiles were similar for men and women. These included a: "Wholegrain cereals and milks" profile (men: $16 \%$, women: $17 \%$ ) as almost all participants with this profile reported consuming wholegrain high fibre cereals. Other foods that featured in this profile, compared to other profiles, were low fat milks, dried fruit, fresh/canned fruit, nuts and seeds and yoghurts/custards. The profile, labelled "Protein-foods", (men; $11 \%$ and women: $11 \%$ ) was characterised by intakes of eggs, processed meats and refined grains or bread and unsaturated oils. Cheeses featured more strongly in the profile and this was the only profile where vegetables, including legumes were represented. The third similar profile for men and women, labelled "Mixed cereals and milks" (men: 33\%, women: 37\%) featured a mix of cereals types (e.g., wholegrain cereals, refined grain cereals and sweetened cereal products) and milks. Fresh fruit was also reported by 19 and 30\% of men and women with this profile, respectively. Two further profiles, labelled "Breads and spreads 1" (men: 23\%, women: 18\%) and "Bread and spreads 2" (men: 15\%, women: $17 \%$ ) were characterized by breads (wholegrain and/or refined grain) and spreads (discretionary and/or unsaturated). However, these two profiles were differentiated by their accompanying beverages (men) or type of grain (women). For example, $90 \%$ of men with a "Breads and spreads 1" profile reported consuming coffee or tea whereas sugar-sweetened beverage intake consumption was highest for the "Breads and spreads 2" profile. Among women with a "Bread and spreads 1" profile, 
Table 2 Energy-adjusted intakes of the key food groups at the breakfast eating occasion according to latent breakfast profile among Australian men $(n=3545)^{a}$

\begin{tabular}{|c|c|c|}
\hline & Percentage $(\%)$ of consumers & Mean $(95 \% \mathrm{Cl})$ intake $(\mathrm{g})$ among consumers \\
\hline Profile 1: "Wholegrain cereals and milks" & 16 & \\
\hline \multicolumn{3}{|l|}{ Food group (g) } \\
\hline Wholegrain high fibre cereals & 99 & $38.4(36.3,40.6)$ \\
\hline Dried fruit & 87 & $10.0(9.2,11.0)$ \\
\hline Reduced fat milks & 51 & $127.3(112.8,143.8)$ \\
\hline Tea or coffee & 51 & $206.9(186.9,229.2)$ \\
\hline Nuts and seeds & 45 & $5.3(4.7,5.9)$ \\
\hline Medium fat milks & 38 & $106.1(93.4,120.5)$ \\
\hline Fresh or canned fruit & 37 & $41.9(31.9,55.1)$ \\
\hline Unsaturated oils & 30 & $2.1(2.0,2.2)$ \\
\hline Water & 24 & $574.2(460.8,715.4)$ \\
\hline Yoghurts and custards & 20 & $64.8(57.1,73.5)$ \\
\hline Profile 2: "Protein-foods" & 11 & \\
\hline \multicolumn{3}{|l|}{ Food group (g) } \\
\hline Unsaturated oils & 69 & $3.9(3.5,4.3)$ \\
\hline Eggs & 61 & $54.9(48.2,62.6)$ \\
\hline All other vegetables & 51 & $34.5(28.5,41.7)$ \\
\hline Tea or coffee & 50 & $235.9(217.4,256.0)$ \\
\hline Refined grain low fibre breads & 49 & $49.7(43.8,56.5)$ \\
\hline Processed meats & 43 & $35.7(32.0,39.8)$ \\
\hline Unsaturated spreads & 43 & $1.9(1.6,2.1)$ \\
\hline Brassica vegetables & 33 & $13.6(10.9,16.9)$ \\
\hline Medium fat milks & 28 & $39.0(32.5,46.7)$ \\
\hline Cheeses & 25 & $16.6(13.7,20.1)$ \\
\hline Water & 21 & $687.1(503.2,938.2)$ \\
\hline Condiments & 20 & $16.4(13.7,19.5)$ \\
\hline Refined low fibre grains & 15 & $17.5(8.0,38.6)$ \\
\hline Profile 3: "Breads and spreads 1" & 23 & \\
\hline \multicolumn{3}{|l|}{ Food group (g) } \\
\hline Tea or coffee & 90 & $205.6(192.9,219.1)$ \\
\hline Discretionary spreads & 65 & $12.2(11.1,13.4)$ \\
\hline Refined grain low fibre breads & 51 & $59.1(54.8,63.8)$ \\
\hline Sugar & 50 & $7.7(7.2,8.4)$ \\
\hline Whole grain high fibre breads & 46 & $55.7(52.3,59.2)$ \\
\hline Medium fat milks & 46 & $52.1(46.3,58.5)$ \\
\hline Unsaturated spreads & 44 & $9.0(8.3,9.7)$ \\
\hline Reduced fat milks & 28 & $53.6(46.4,62.0)$ \\
\hline Water & 16 & $637.5(483.3,844.2)$ \\
\hline Profile 4: "Mixed cereals and milks" & 33 & \\
\hline \multicolumn{3}{|l|}{ Food group (g) } \\
\hline Medium fat milks & 50 & $154.6(143.6,166.5)$ \\
\hline Tea or coffee & 44 & $236.6(221.9,252.3)$ \\
\hline Whole grain high fibre cereals & 38 & $48.6(46.2,51.2)$ \\
\hline
\end{tabular}


Table 2 Energy-adjusted intakes of the key food groups at the breakfast eating occasion according to latent breakfast profile among Australian men $(n=3545)^{\text {a }}$ (Continued)

\begin{tabular}{lll}
\hline & Percentage (\%) of consumers & Mean $\mathbf{( 9 5 \% ~ C l ) ~ i n t a k e ~} \mathbf{( g )}$ among consumers \\
\hline Sugar & 37 & $10.8(10.0,11.6)$ \\
Reduced fat milks & 32 & $159.2(140.3,180.7)$ \\
Fresh or canned fruit & 19 & $100.3(80.2,125.4)$ \\
Water & 19 & $692.4(564.2,849.6)$ \\
Whole grain high fibre grains & 17 & $191.0(169.5,215.3)$ \\
Refined grain low fibre cereals & 17 & $36.0(32.9,39.4)$ \\
Profile 5: "Breads and spreads 2" & 15 & \\
Food group (g) & 41 & $65.5(61.0,70.4)$ \\
Refined grain low fibre breads & 39 & $10.6(8.9,12.7)$ \\
Discretionary spreads & 34 & $67.6(62.0,73.8)$ \\
Wholegrain high fibre breads & 25 & $8.8(7.2,10.7)$ \\
Unsaturated spreads & 24 & $1080.2(792.0,1473.2)$ \\
Water & 17 & $2.8(2.3,3.3)$ \\
Unsaturated oils & 16 & $167.7(110.1,255.5)$ \\
Sugar-sweetened beverages &
\end{tabular}

${ }^{a}$ Values shown are weighted percentage (\%) of women who reported consuming one or more food/beverage items from each food group and weighted geometric mean ( $95 \%$ confidence interval) intakes $(\mathrm{g})$ of energy-adjusted food groups

almost all women consumed wholegrain breads whereas refined grain breads were consumed by all women with the "Breads and spreads 2" profile. Added sugar featured most strongly in profiles with the highest tea or coffee consumption (i.e., "Breads and Spreads 1" for men and "Breads and spreads 2" for women). Complete data on the intake of all 35 food group variables, overall and by latent breakfast profile, are provided in Additional Files 5 and 6.

\section{Time of consumption of latent breakfast food profiles}

The consumption of breakfast food profiles for men and women differed by day of the week (weekend $\mathrm{v}$ weekday) and time-of-day (Table 4). In both men and women, a higher proportion of breakfast occasions characterised by "Protein-foods" were consumed after 9:00 h, and on the weekend, when compared to the other breakfast profiles. Irrespective of the breakfast profile, breakfast occasions tended to occur later on the weekend, than on weekdays, and a higher percentage of men, compared to women, reported a breakfast occasion before 7:00 h.

\section{Participant characteristics of latent breakfast food profiles}

Table 5 presents the characteristics of Australian men and women, overall and by latent breakfast food profile. The mean ages of men and women were $47.0 \mathrm{y}$ and 48.5 $y$, respectively. Over two thirds of men and women were born in Australia and were more likely to have a medium education level, live in major Australian cities and be married or in a defacto relationship. Compared with the other profiles, men with a "Wholegrain cereals and milks" or "Bread and Spreads 1" profile were older and a higher proportion were married. Men with a "Wholegrain cereals and milks" profile had higher education and income levels, a lower proportion were current smokers and a higher proportion were born in Australia, whereas men with a "Breads and spreads 1" profile had lower education and income levels, lived in an inner regional/rural city, and a higher proportion did not work in the previous week. Among women, those with a "Protein-centred" profile were younger and a higher proportion were born in a non-English speaking country, unmarried and worked $<40 \mathrm{~h}$ in the previous week. Women with a "Wholegrain cereals and milks" or either of the "Bread and spreads" profiles were older and, as per men, women with a "Wholegrain cereals and milks profile" were more likely to be born in Australia, meet physical activity guidelines and less likely to be current smokers, however, no associations were found for education or income level. Women with the "Wholegrain cereals and milks" and "Breads and Spreads 1" profiles were also more likely to be married.

\section{Adiposity characteristics of latent breakfast food profiles}

Differences in adjusted adiposity estimates by latent breakfast food profile are presented in Table 6. Both men and women with a "Wholegrain cereals and milks" profile had the most favourable estimates for BMI and WC and overweight/obesity prevalence, when compared to the other profiles. However, among men with a 
Table 3 Energy-adjusted intakes of the key food groups at the breakfast eating occasion according to latent breakfast profile among Australian women $(n=4127)^{\mathrm{a}}$

\begin{tabular}{|c|c|c|}
\hline & Percentage (\%) of consumers & Mean $(95 \% \mathrm{Cl})$ intake $(\mathrm{g})$ among consumers \\
\hline Profile 1: "Wholegrain cereals and milks" & 17 & \\
\hline \multicolumn{3}{|l|}{ Food group (g) } \\
\hline Wholegrain high fibre cereals & 99 & $37.3(35.7,38.9)$ \\
\hline Dried fruit & 86 & $9.8(9.1,10.5)$ \\
\hline Reduced fat milks & 59 & $109.3(99.4,120.2)$ \\
\hline Tea or coffee & 55 & $223.6(202.1,247.5)$ \\
\hline Nuts and seeds & 49 & $5.4(4.9,6.0)$ \\
\hline Fresh or canned fruit & 41 & $37.7(29.6,48.0)$ \\
\hline Medium fat milks & 25 & $99(84.1,116.7)$ \\
\hline Yoghurts and custards & 25 & $65.0(57.5,73.5)$ \\
\hline Water & 23 & $642.1(504.0,818.2)$ \\
\hline Profile 2: "Protein-foods" & 11 & \\
\hline \multicolumn{3}{|l|}{ Food group (g) } \\
\hline Unsaturated oils & 56 & $3.9(3.4,4.4)$ \\
\hline All other vegetables & 46 & $31.4(25.0,39.4)$ \\
\hline Eggs & 43 & $56.0(47.9,65.5)$ \\
\hline Tea or coffee & 41 & $220.6(192.9,252.3)$ \\
\hline Refined grain low fibre breads & 36 & $51.3(45.2,58.2)$ \\
\hline Unsaturated spreads & 36 & $2.1(1.7,2.6)$ \\
\hline Medium fat milks & 29 & $43.2(31.5,59.3)$ \\
\hline Brassica vegetables & 28 & $16.0(11.4,22.4)$ \\
\hline Refined low fibre grains & 26 & $15.7(10.3,23.9)$ \\
\hline Processed meats & 26 & $29.1(25.8,32.8)$ \\
\hline Water & 24 & $850.2(670.41078 .3)$ \\
\hline Orange vegetables & 22 & $11.5(8.0,16.4)$ \\
\hline Starchy vegetables & 21 & $13.5(7.2,25.2)$ \\
\hline Cheeses & 18 & $18.5(15.5,22.0)$ \\
\hline Profile 3: "Breads and spreads 1" & 18 & \\
\hline \multicolumn{3}{|l|}{ Food group (g) } \\
\hline Whole grain high fibre breads & 99 & $55.5(53.5,57.6)$ \\
\hline Tea or coffee & 66 & $211.3(199.7,223.6)$ \\
\hline Discretionary spreads & 60 & $10.7(9.7,11.8)$ \\
\hline Unsaturated spreads & 39 & $6.6(6.0,7.3)$ \\
\hline Reduced fat milks & 35 & $55.3(48.1,63.7)$ \\
\hline Medium fat milks & 22 & $60.0(48.7,73.9)$ \\
\hline Sugar & 22 & $5.8(5.2,6.4)$ \\
\hline Water & 16 & $745.7(584.9,950.7)$ \\
\hline Profile 4: "Mixed cereals and milks" & 37 & \\
\hline \multicolumn{3}{|l|}{ Food group (g) } \\
\hline Tea or coffee & 51 & $221.2(208.2,235.1)$ \\
\hline Reduced fat milks & 38 & $130.6(119.2,143.1)$ \\
\hline Medium fat milks & 37 & $140.6(128.4,153.9)$ \\
\hline Fresh or canned fruit & 30 & $87.6(75.7,101.4)$ \\
\hline
\end{tabular}


Table 3 Energy-adjusted intakes of the key food groups at the breakfast eating occasion according to latent breakfast profile among Australian women $(n=4127)^{\mathrm{a}}$ (Continued)

\begin{tabular}{lll}
\hline & Percentage (\%) of consumers & Mean $\mathbf{( 9 5 \% ~ C l ) ~ i n t a k e ~ ( g ) ~ a m o n g ~ c o n s u m e r s ~}$ \\
\hline Whole grain high fibre grains & 27 & $192.0(180.3,204.4)$ \\
Sugar & 27 & $8.9(8.1,9.8)$ \\
Whole grain high fibre cereals & 24 & $42.2(40.4,44.1)$ \\
Water & 23 & $657.0(556.8,775.3)$ \\
Refined grain low fibre cereals & 14 & $36.0(33.8,38.3)$ \\
Profile 5: "Breads and spreads 2" & 17 & \\
Food group (g) & 100 & $55.2(52.8,57.8)$ \\
Refined grain low fibre breads & 68 & $215.3(193.4,239.6)$ \\
Tea or coffee & 62 & $11.8(10.7,12.9)$ \\
Discretionary spreads & 36 & $7.9(7.2,8.7)$ \\
Unsaturated spreads & 30 & $6.9(6.3,7.5)$ \\
Sugar & 27 & $46.5(39.1,55.3)$ \\
Reduced fat milks & 24 & $60.4(52.0,70.2)$ \\
Medium fat milks & 17 & $567.2(430.8,746.7)$ \\
Water
\end{tabular}

${ }^{2}$ Values shown are weighted percentage (\%) of women who reported consuming one or more food/beverage items from each food group and weighted geometric mean ( $95 \%$ confidence interval) intakes ( $\mathrm{g}$ ) of energy-adjusted food groups

"Wholegrain cereals and milks" profile, BMI and WC were only statistically significantly lower than men with either of the "Breads and spreads" (1 or 2) profile. Women with a "Wholegrain cereals and milks" had lower BMI and WC when compared to the "Mixed cereals and milks" profile and also a lower WC when compared to the "Protein-foods" and "Breads and Spreads 2" profiles. No statistically significant differences between breakfast profiles were found for the prevalence of overweight/obesity among either men or women.

\section{Discussion}

Using a LVMM approach, this study explored the combinations of foods eaten at the breakfast eating occasion in a nationally representative sample of Australian men and women. This is one the few studies among adults to use a data-driven method to understand how foods are consumed in relation to each other at eating occasions, and highlights breakfast-specific differences in diet quality. Five distinct breakfast food profiles were found among men and women, and these profiles varied by time of consumption, participant characteristics and adiposity indicators.

Our finding of five unique breakfast food profiles that were associated with timing of consumption, participant characteristics and adiposity measures underscores the usefulness of LVMM to objectively capture the permutations of food combinations at eating occasions. Exploratory and data-driven approaches are useful because they do not rely on a set of arbitrary criteria or researcher- driven assumptions to understand how people combine foods together to make a meal (i.e. meal patterns).

Few studies have examined food profiles at specific eating occasions using a data-driven approach [17-19]. Applying supervised data mining techniques to 51 food groups, Hearty and Gibney found that common food combinations at breakfast were: bread with eggs/meat products; bread and breakfast cereal; and bread or breakfast cereal (and/or both) together with fruit/juice; bread and breakfast among Irish adults [17]. In another national study of Irish adults, Woolhead et al. used frequent-sets data mining methods to identify common food combinations, based on 20 food groups, to aggregate dietary data into generic meals at eating occasions [18]. Most frequent combinations for the breakfast eating occasion included cereals and milk, often paired with bread, fruit and/or juice, and breads with "cooked breakfast" (not further defined), egg, fruit or juice. Schwedhelm et al. used Gaussian graphical models to understand the interrelations between foods at meals, including breakfast, in German adults [19]. Cereals were found to link strongly together with nuts and links with fresh fruits and legumes were also found. Two profiles were observed where bread was the central food, consumed together with spreads (i.e. margarine, butter and sugar \& confectionery) or with processed meat and cheese. Milk/dairy foods and eggs were not assigned to a profile but were linked with cereals and bread, respectively. Vegetables also featured and linked together with meat (either processed or lean) and sauces [19]. While 
Table 4 Percentage of breakfast food profiles consumed according to the type of day (weekend vs. weekday) and time-period of the day among Australian men and women breakfast consumers ${ }^{\mathrm{a}, \mathrm{b}, \mathrm{c}}$

\begin{tabular}{|c|c|c|c|c|c|c|c|}
\hline & $\begin{array}{l}\text { All } \\
\text { breakfasts }\end{array}$ & $\begin{array}{l}\text { Wholegrain cereals \& } \\
\text { milks }\end{array}$ & $\begin{array}{l}\text { Protein- } \\
\text { foods }\end{array}$ & $\begin{array}{l}\text { Bread \& } \\
\text { spreads } 1\end{array}$ & $\begin{array}{l}\text { Mixed cereals \& } \\
\text { milks }\end{array}$ & $\begin{array}{l}\text { Bread \& } \\
\text { spreads } 2\end{array}$ & $P$ value \\
\hline & & Men $(n=3545)$ & & & & & \\
\hline Day of the week (\%) & & & & & & & $<0.001$ \\
\hline $\begin{array}{l}\text { Monday to Friday } \\
\text { (weekday) }\end{array}$ & 77 & 81 & 67 & 75 & 80 & 75 & \\
\hline $\begin{array}{l}\text { Saturday/Sunday } \\
\text { (weekend) }\end{array}$ & 23 & 19 & 33 & 25 & 20 & 25 & \\
\hline Weekday time-period (\%) & & & & & & & $<0.001$ \\
\hline$<7: 00$ & 26 & 30 & 15 & 23 & 31 & 21 & \\
\hline $7: 00$ to $7: 59$ & 30 & 36 & 20 & 40 & 28 & 22 & \\
\hline $8: 00$ to $8: 59$ & 23 & 21 & 25 & 21 & 23 & 24 & \\
\hline$\geq 9: 00$ & 21 & 13 & 40 & 16 & 18 & 33 & \\
\hline Weekend time-period (\%) & & & & & & & 0.08 \\
\hline$<7: 00$ & 12 & 18 & 6 & 11 & 14 & 8 & \\
\hline $7: 00$ to $7: 59$ & 19 & 24 & 14 & 22 & 18 & 19 & \\
\hline $8: 00$ to $8: 59$ & 26 & 26 & 21 & 30 & 28 & 24 & \\
\hline \multirow[t]{2}{*}{$\geq 9: 00$} & 43 & 32 & 59 & 37 & 40 & 49 & \\
\hline & & Women $(n=4127)$ & & & & & \\
\hline Day of the week (\%) & & & & & & & $<0.001$ \\
\hline Monday to Friday & 80 & 82 & 70 & 84 & 77 & 80 & \\
\hline Saturday/Sunday & 20 & 18 & 30 & 16 & 23 & 23 & \\
\hline Weekday time-period (\%) & & & & & & & $<0.001$ \\
\hline$<7: 00$ & 15 & 16 & 9 & 16 & 16 & 14 & \\
\hline $7: 00$ to $7: 59$ & 34 & 42 & 22 & 34 & 34 & 32 & \\
\hline $8: 00$ to $8: 59$ & 28 & 27 & 30 & 28 & 28 & 30 & \\
\hline$\geq 9: 00$ & 23 & 14 & 39 & 22 & 22 & 24 & \\
\hline Weekend time-period (\%) & & & & & & & $<0.001$ \\
\hline$<7: 00$ & 8 & 8 & 2 & 8 & 12 & 7 & \\
\hline $7: 00$ to $7: 59$ & 22 & 41 & 11 & 23 & 16 & 24 & \\
\hline $8: 00$ to $8: 59$ & 33 & 27 & 27 & 36 & 39 & 32 & \\
\hline$\geq 9: 00$ & 37 & 24 & 60 & 33 & 33 & 37 & \\
\hline
\end{tabular}

${ }^{a}$ Values are weighted percentages

${ }^{b}$ Weekday vs weekend and time-of-day differences between breakfast profiles for were assessed using an adjusted Pearson Chi2 test 'The Breads and spreads profiles were differentiated by their accompanying beverages for men (Profile 1: coffee/tea; Profile 2: Sugar-sweetened beverages) and by bread grain varieties for women (Profile 1: wholegrain; Profile 2: refined grain)

direct comparisons between these studies and the present study are limited due to differences in the number and type of food group input variables and analytic methods used; there are some shared characteristics of the observed food combinations, including cereals with fruit [17-19] and nuts [19], breads with spreads [19], eggs $[17,19]$ and processed meat $[17,19]$ and vegetables with meat [19]. However, these breakfast combinations are based on dietary data collected in Western populations and breakfast food profiles are likely to differ across cultures [16, 44, 45]; country-specific studies are needed for the development of meal-specific advice that reflects social, cultural and dietary preferences.

In the present study, sex differences and weekend vs weekday differences in the timing of the breakfast occasion were observed and may be indicative of different work routines and schedules [46]. Further, a breakfast food profile characterised by "Protein-foods" occurred more frequently on weekends and later in the morning (irrespective of the day of the week), when compared to the other food profiles. As protein-foods such meat and eggs may require more preparation and cooking time 
Table 5 Sociodemographic and health characteristics of Australian men and women breakfast consumers and their associations with breakfast food profiles $^{1-3}$

\begin{tabular}{|c|c|c|c|c|c|c|c|}
\hline & $\begin{array}{l}\text { All breakfast } \\
\text { consumers }\end{array}$ & $\begin{array}{l}\text { Wholegrain cereals } \\
\& \text { milks }\end{array}$ & $\begin{array}{l}\text { Protein- } \\
\text { foods }\end{array}$ & $\begin{array}{l}\text { Bread \& } \\
\text { spreads } 1\end{array}$ & $\begin{array}{l}\text { Mixed cereals } \\
\& \text { milks }\end{array}$ & $\begin{array}{l}\text { Bread \& } \\
\text { spreads } 2\end{array}$ & $P$ value \\
\hline & & Men $(n=3545)$ & & & & & \\
\hline $\begin{array}{l}\text { Age (years, mean ( } 95 \% \\
\text { confidence interval)) }\end{array}$ & $47.0(46.6,47.4)$ & $49.6(47.7,51.5)^{a}$ & $\begin{array}{l}42.7(41.0 \\
44.4)^{\mathrm{bd}}\end{array}$ & $\begin{array}{l}54.7(53.2, \\
56.1)^{c}\end{array}$ & $45.1(43.9,46.2)^{d}$ & $\begin{array}{l}40.2(38.5 \\
41.9)^{\text {be }}\end{array}$ & $<0.001$ \\
\hline Country of birth (\%) & & & & & & & $<0.001$ \\
\hline Australia & 68 & 74 & 61 & 69 & 69 & 65 & \\
\hline Mainly English speaking & 12 & 13 & 10 & 13 & 13 & 8 & \\
\hline All other countries & 20 & 12 & 29 & 18 & 18 & 27 & \\
\hline Education level (\%) & & & & & & & $<0.05$ \\
\hline Low & 22 & 17 & 20 & 26 & 23 & 23 & \\
\hline Medium & 53 & 51 & 55 & 53 & 55 & 53 & \\
\hline High & 25 & 32 & 25 & 21 & 22 & 25 & \\
\hline Weekly income (quintiles, \%) ${ }^{4}$ & & & & & & & $<0.05$ \\
\hline First: $<\$ 398$ & 16 & 13 & 13 & 21 & 17 & 16 & \\
\hline Second: \$399-638 & 16 & 13 & 19 & 19 & 15 & 13 & \\
\hline Third: \$639-958 & 21 & 19 & 21 & 20 & 20 & 24 & \\
\hline Fourth: \$959-1438 & 23 & 27 & 22 & 20 & 24 & 24 & \\
\hline Fifth: $\geq \$ 1439$ & 24 & 28 & 25 & 21 & 24 & 22 & \\
\hline Geographic region (\%) & & & & & & & $<0.001$ \\
\hline Major cities of Australia & 70 & 73 & 73 & 63 & 71 & 74 & \\
\hline Inner regional cities & 20 & 17 & 15 & 25 & 20 & 19 & \\
\hline Other areas (rural/remote) & 10 & 10 & 12 & 12 & 9 & 8 & \\
\hline Social status (\%) & & & & & & & $<0.001$ \\
\hline Married & 64 & 71 & 58 & 72 & 60 & 57 & \\
\hline Not married & 36 & 29 & 42 & 28 & 41 & 43 & \\
\hline Hours worked (past week, \%) & & & & & & & $<0.001$ \\
\hline None & 33 & 31 & 29 & 45 & 31 & 23 & \\
\hline$<40 \mathrm{~h}$ & 27 & 28 & 26 & 22 & 27 & 32 & \\
\hline$\geq 40 \mathrm{~h}$ & 41 & 41 & 44 & 33 & 43 & 45 & \\
\hline Smoking status (\%) & & & & & & & $<0.001$ \\
\hline Current smoker & 16 & 10 & 26 & 14 & 16 & 19 & \\
\hline Former smoker & 37 & 38 & 36 & 46 & 34 & 29 & \\
\hline Never smoker & 47 & 52 & 39 & 40 & 49 & 52 & \\
\hline \multirow[t]{2}{*}{ Met PA guidelines $(\%)^{5}$} & 45 & 51 & 43 & 42 & 42 & 50 & $<0.05$ \\
\hline & & Women $(n=4127)$ & & & & & \\
\hline $\begin{array}{l}\text { Age }(y, \text { mean ( } 95 \% \text { confidence } \\
\text { interval)) }\end{array}$ & $48.5(48.1,48.9)$ & $52.1(50.1,54.1)^{a}$ & $\begin{array}{l}40.9(38.8 \\
43.0)^{b}\end{array}$ & $\begin{array}{l}52.0(50.0 \\
54.1)^{\mathrm{a}}\end{array}$ & $47.1(46.2,48.1)^{c}$ & $\begin{array}{l}49.1(47.2 \\
50.9)^{\mathrm{ac}}\end{array}$ & $<0.001$ \\
\hline Country of birth (\%) & & & & & & & $<0.001$ \\
\hline Australia & 70 & 76 & 60 & 70 & 70 & 69 & \\
\hline Mainly English speaking & 11 & 13 & 8 & 12 & 12 & 9 & \\
\hline All other countries & 19 & 11 & 32 & 18 & 18 & 22 & \\
\hline Education level (\%) & & & & & & & 0.09 \\
\hline Low & 29 & 30 & 21 & 30 & 28 & 33 & \\
\hline Medium & 43 & 42 & 51 & 44 & 42 & 42 & \\
\hline
\end{tabular}


Table 5 Sociodemographic and health characteristics of Australian men and women breakfast consumers and their associations with breakfast food profiles $^{1-3}$ (Continued)

\begin{tabular}{|c|c|c|c|c|c|c|c|}
\hline & $\begin{array}{l}\text { All breakfast } \\
\text { consumers }\end{array}$ & $\begin{array}{l}\text { Wholegrain cereals } \\
\text { \& milks }\end{array}$ & $\begin{array}{l}\text { Protein- } \\
\text { foods }\end{array}$ & $\begin{array}{l}\text { Bread \& } \\
\text { spreads } 1\end{array}$ & $\begin{array}{l}\text { Mixed cereals } \\
\& \text { milks }\end{array}$ & $\begin{array}{l}\text { Bread \& } \\
\text { spreads } 2\end{array}$ & $P$ value \\
\hline High & 28 & 28 & 28 & 26 & 30 & 25 & \\
\hline Weekly income (quintiles, \%) & & & & & & & 0.06 \\
\hline First: $<\$ 398$ & 21 & 17 & 24 & 22 & 21 & 23 & \\
\hline Second: \$399-638 & 19 & 21 & 13 & 22 & 19 & 21 & \\
\hline Third: \$639-958 & 19 & 18 & 20 & 20 & 18 & 22 & \\
\hline Fourth: \$959-1438 & 21 & 23 & 21 & 21 & 21 & 20 & \\
\hline Fifth: $\geq \$ 1439$ & 19 & 22 & 23 & 16 & 21 & 14 & \\
\hline Geographic region (\%) & & & & & & & 0.46 \\
\hline Major cities of Australia & 73 & 73 & 78 & 69 & 72 & 73 & \\
\hline Inner regional cities & 18 & 19 & 13 & 21 & 18 & 18 & \\
\hline Other areas (rural/remote) & 9 & 8 & 9 & 10 & 9 & 9 & \\
\hline Social status (\%) & & & & & & & $<0.01$ \\
\hline Married/defacto & 58 & 62 & 51 & 59 & 56 & 65 & \\
\hline Not married & 42 & 38 & 49 & 41 & 44 & 35 & \\
\hline Hours worked (past week, \%) & & & & & & & $<0.01$ \\
\hline None & 46 & 47 & 40 & 51 & 43 & 49 & \\
\hline$<40 h$ & 37 & 38 & 43 & 33 & 37 & 38 & \\
\hline$\geq 40 \mathrm{~h}$ & 17 & 15 & 17 & 16 & 20 & 14 & \\
\hline Smoking status (\%) & & & & & & & $<0.05$ \\
\hline Current smoker & 13 & 9 & 14 & 15 & 13 & 13 & \\
\hline Former smoker & 28 & 32 & 25 & 30 & 26 & 27 & \\
\hline Never smoker & 59 & 59 & 61 & 55 & 61 & 60 & \\
\hline Met PA guidelines $(\%)^{5}$ & 42 & 49 & 44 & 43 & 42 & 36 & $<0.05$ \\
\hline
\end{tabular}

${ }^{1}$ Values are weighted means (95\% confidence interval) for continuous variables and weighted proportions for categorical variables

${ }^{2}$ Different superscript letters indicate significant differences between profiles, assessed using a $F$-test with Bonferroni correction for continuous variables.

Differences between profiles for categorical variables were assessed using an adjusted Pearson Chi2 test

${ }^{3}$ The Breads and spreads profiles were differentiated by their accompanying beverages for men (Profile 1: coffee/tea; Profile 2: Sugar-sweetened beverages) and

by bread grain varieties for women (Profile 1: wholegrain; Profile 2: refined grain)

${ }^{4} n=2258$ men and $n=2586$ women due to missing cases for income

${ }^{5}$ Whether met physical activity (PA) guidelines of $150 \mathrm{~min}$ and 5 sessions per week

than cereals or breads, this suggests that timeavailability may be an important factor in determining food intakes at breakfast. Whilst in the present study, women with a "Protein-foods profiles" were more likely to work less than $40 \mathrm{~h}$ a week and be unmarried. Contextual information regarding location of eating, meal preparation, sharing of meals and perception of time-availability are needed to better understand the factors that influence food choices and diet quality at eating occasions $[47,48]$.

Studies investigating the participant characteristics of breakfast food profiles among adults are rare and have compared breakfasts comprising "ready-to-eat" cereals versus "all other" breakfasts [49] or different breakfasts patterns based on common foods [50] in nationallyrepresentative samples of adults from the U.S. In all of these studies, consumption of breakfast cereals was positively associated with indicators of ethnicity (white $[49,50]$, speaking English at home [49]) and socioeconomic position (food security [49], income [50] and education [50]). Age was also positively linked to breakfast cereal consumption in one study [49]. While these finding are difficult to compare to the present study which provided a detailed examination of food combinations at breakfast, some similarities are observed. For example, we found that adults with a "Wholegrain cereals and milks" profile tended to be older and born in Australia, and among men, more highly educated. Compared to other breakfast types, Siega-Riz et al. found that breakfasts comprising egg as the main food were associated with being black or Hispanic and lower education, when compared to other breakfast types [50]. In the present study, both men and women with a "Protein-foods" profile (which included eggs) were more likely to be 
Table 6 Adiposity characteristics of Australian men and women breakfast consumers and their associations with breakfast food profiles $^{1-3}$

\begin{tabular}{|c|c|c|c|c|c|c|}
\hline & $\begin{array}{l}\text { All breakfast } \\
\text { consumers }\end{array}$ & $\begin{array}{l}\text { Wholegrain cereals \& } \\
\text { milks }\end{array}$ & $\begin{array}{l}\text { Protein- } \\
\text { foods }\end{array}$ & $\begin{array}{l}\text { Bread \& } \\
\text { spreads } 1\end{array}$ & $\begin{array}{l}\text { Mixed cereals \& } \\
\text { milks }\end{array}$ & $\begin{array}{l}\text { Bread \& } \\
\text { spreads } 2\end{array}$ \\
\hline & \multicolumn{6}{|c|}{ Men $^{5}$} \\
\hline $\mathrm{BMI}^{4}, \mathrm{~kg} / \mathrm{m}^{2}$ & $27.2(27.0,27.4)$ & $26.6(26.2,27.1)^{a}$ & $\begin{array}{l}27.1(26.6 \\
27.7)\end{array}$ & $\begin{array}{l}27.8(27.3 \\
28.2)^{\mathrm{b}}\end{array}$ & $27.0(26.6,27.3)^{\mathrm{a}}$ & $\begin{array}{l}27.8(27.2 \\
28.4)^{b}\end{array}$ \\
\hline $\mathrm{BMI} \geq 25 \mathrm{~kg} / \mathrm{m}^{2}, \%$ & $71(68.6,73.6)$ & $68.9(62.9,74.8)$ & $\begin{array}{l}69.5(63.7 \\
75.3)\end{array}$ & $75.0(70.4,79.4)$ & $69.9(61.1,73.6)$ & $71.6(65.0,78.1)$ \\
\hline Waist circumference, $\mathrm{cm}$ & $97.9(97.3,98.5)$ & $95.4(94.1,96.8)^{a}$ & $\begin{array}{l}97.8(96.2 \\
99.4)^{\mathrm{b}}\end{array}$ & $\begin{array}{l}99.4(98.2 \\
100.5)^{b}\end{array}$ & $97.2(96.1,98.3)^{a}$ & $\begin{array}{l}99.9(98.2 \\
101.5)^{b}\end{array}$ \\
\hline \multirow[t]{2}{*}{$\begin{array}{l}\text { Waist circumference, cm } \\
\geq 94 \mathrm{~cm}, \%\end{array}$} & $61.6(58.7,64.5)$ & $58.3(51.7,64.9)$ & $\begin{array}{l}63.1(56.1 \\
70.2)\end{array}$ & $\begin{array}{l}66.4(61.4 \\
71.4)^{\mathrm{b}}\end{array}$ & $58.5(53.3,63.8)$ & $63.3(56.7,70.0)$ \\
\hline & Women $^{6}$ & & & & & \\
\hline $\mathrm{BMl}^{4}, \mathrm{~kg} / \mathrm{m}^{2}$ & $26.4(26.1,26.6)$ & $25.6(25.1,26.1)^{a}$ & $\begin{array}{l}26.3(25.1 \\
27.0)\end{array}$ & $26.3(25.7,26.9)$ & $26.9(26.4,27.4)^{b}$ & $26.2(25.6,26.8)$ \\
\hline $\mathrm{BMI} \geq 25 \mathrm{~kg} / \mathrm{m}^{2}, \%$ & $56.2(53.2,59.2)$ & $50.7(43.9,57.6)$ & $\begin{array}{l}56.1(48.0, \\
64.2)\end{array}$ & $58.4(52.6,64.2)$ & $58.9(54.3,63.5)^{b}$ & $53.9(48.0,59.8)$ \\
\hline Waist circumference, $\mathrm{cm}$ & $87.5(86.8,88.3)$ & $85.5(84.1,86.9)^{a}$ & $\begin{array}{l}88.1(86.3 \\
90.0)^{b}\end{array}$ & $87.6(86.0,89.1)$ & $88.3(87.1,89.5)^{b}$ & $\begin{array}{l}87.5(86.1 \\
89.0)^{b}\end{array}$ \\
\hline $\begin{array}{l}\text { Waist circumference, cm } \\
\geq 80 \mathrm{~cm}, \%\end{array}$ & $68.5(65.9,71.1)$ & $64.6(57.8,71.5)$ & $\begin{array}{l}71.9(64.8, \\
78.9)\end{array}$ & $69.0(64.1,74.0)$ & $69.2(65.0,73.4)$ & $68.1(62.9,73.1)$ \\
\hline
\end{tabular}

${ }^{1}$ Values are weighted means (95\% confidence intervals) for continuous variables and weighted percentages (95\% confidence intervals) for categorical variables adjusted for age, education level, smoking status, meeting physical activity guidelines and energy intake at all eating occasions outside of breakfast ${ }^{2}$ Different superscript letters indicate significant pairwise differences between breakfast profiles after applying the Bonferroni correction ( $p<0.05$ )

${ }^{3}$ The Breads and spreads profiles were differentiated by their accompanying beverages for men (Profile 1: coffee/tea; Profile 2: Sugar-sweetened beverages) and by bread grain varieties for women (Profile 1: wholegrain; Profile 2: refined grain)

${ }^{4}$ Values for BMI (continuous variable) are weighted geometric means ( $95 \%$ confidence interval)

${ }^{5} n=3061$ with no missing data for BMI and $n=3068$ with no missing data for waist circumference

${ }^{6} n=3431$ with no missing data for BMI and $n=3414$ with no missing data for waist circumference

younger and born in a non-English speaking country and men with a "Bread and spreads 1" (which included tea/coffee) profile were older and had lower education and income and were more likely to live regionally. In contrast to our study, Barr et al. found no association between breakfast cereal consumption and marital status [49]. However, the present study examined wholegrain cereals and refined cereals as separate food groups, and in combination with other (more or less nutritious) foods, which may explain the different findings. Nonetheless, overall these results indicate that the sociocultural influences on food choices at breakfast are complex and may differ for men and women. Further research, including those with qualitative study designs, is needed to elucidate the factors that influence food choices and preferences so that approaches to improve breakfast diet quality can be tailored more effectively.

A wealth of research has focused on the health impacts of breakfast skipping, particularly weight-related outcomes with fewer studies examining the types and combinations of foods consumed at breakfast [35, 49, 51]. In the present study, men and women with a "Wholegrain cereals and milks" profile, which featured fruit, dried fruit, nuts and seeds and/or yoghurt, consistently had the lowest adiposity measures. This finding is in line with previous research that showed North American adults who consumed ready-to-eat cereals [33, 49] and breakfasts that included grains/cereals, reduced fat milks and/or fruit [35] had a more favourable BMI [33, $35]$ and WC [33, 35]. While the present cross-sectional analysis adjusted for energy intake and a number of important lifestyle confounders, a causal link between breakfast consumption and obesity has not been established [52]. Both breakfast consumption and breakfast quality are associated with other lifestyle factors such as better overall diet quality $[7,17,35,51]$, higher physical activity $[49,53]$ and non-smoking status $[49,53,54]$. In the present study, men and women with the "Wholegrain cereals and milks" profile had the lowest representation of current smokers and the highest representation meeting national physical activity guidelines. Further, a recent gene-wide association study using the UK Biobank data reported genetic links between skipping breakfast (defined as not eating any breakfast cereal on the previous day) and a higher BMI, more depressive symptoms and smoking status [55]. In the same study, genetically defined evening chronotype (i.e., being an evening person) predicted breakfast skipping. Thus, it is possible that the breakfast's contribution to health is, in part due to, its association with an overall healthier 
lifestyle. The link between circadian clock regulation and habitual breakfast consumption, and in the context of sleep-wake and meal timing pattens, also merits investigation in future longitudinal studies.

A limitation of the present study is the breakfast food profiles were determined using a data-driven method that did not allow for the use of survey replicate weights and may limit the generalizability of findings beyond the study sample, including populations from other countries. In addition, little is known about the accuracy of self-reported eating patterns. Dietary intake at breakfast in this study was assessed using a single 24-h dietary recall which is prone to measurement error (e.g., portion size estimation, recall bias and underreporting of food intakes) and is unlikely to capture day-to-day variability in breakfast food profiles $[56,57]$. Whilst the dietary recall varied by day of the week and allowed comparison of breakfast profiles according to weekday and weekend days, Sundays were underrepresented, and thus dietary intakes may not be representative of weekend intakes [57]. Further investigation is needed to understand how breakfast food profiles vary from day-to-day, including shorter term variations (e.g., weekend/weekday patterns, seasonal patterns) and longer term, across life-stages. Breakfast was also classified based on participantidentification of eating occasions, and not the time-ofday, which involves subjectivity in participants' allocation of breakfast as their first eating occasion of the day. The researcher must also decide how to categorise eating occasions that are not clearly defined as breakfast (e.g., brunch), but are often treated as breakfast in studies because they are the first eating occasion of the day. Another subjective aspect is the categorisation of foods and beverages prior to analysis and is considered an impediment to comparing results across studies of dietary patterns [58]. The present study also focussed only on foods consumed at the breakfast occasion; we did not examine the absence of breakfast or profiles of food combinations at other eating occasions across the day. The cross-sectional design of this study also limits our ability to infer any causal relationships between breakfast profiles and adiposity. Further longitudinal investigation of different eating occasions, including their associations with sociodemographic and health indicators, is warranted.

A key strength of the present study was the objective LVMM approach to capture the variability of possible food combinations at breakfast eating occasions using nationally representative dietary data that reflects population intakes of Australian men and women aged 19 years and over. The present analysis examined population food group intakes at breakfast using a food classification scheme developed by the ABS that aligned with Australia's current Dietary Guidelines. The identified breakfast profiles can be used to provide insight into what foods could be added or replaced at the breakfast eating occasions (e.g., targeted and meal-specific dietary advice) in order to recommend feasible dietary changes within particular styles of eating and improve the nutritional quality of the diet. For example, meal-specific messages that encourage the replacement of refinedgrain cereals or breads with wholegrain varieties [59], processed meats with unprocessed meats [60] and the addition of vegetables (to quality protein foods) or nuts, fruit and yoghurts (to cereals) are other examples where breakfast quality could be improved. The person-centred approach of LVMM also provides useful information about sub-populations with suboptimal intake of specific foods at eating occasions and who could be targeted as part of public health strategies. For example, older Australian men who live in regional centres and consume mainly breads and spreads at breakfast may be an important group to target with messages to increase intake of protein rich foods as part of broader strategies to promote healthy aging [61]. Finally, meal and eating occasion profiles may inform modelling of dietary patterns in the translation of dietary guideline and nutrient reference values when developing food guides and other public health nutrition tools through the understanding of consumer behaviour and preferences [62, 63].

In conclusion, LVMM was a novel and useful approach for capturing the complexity of food combinations at eating occasions. Five distinct breakfast food profiles that varied by time of consumption, participant characteristics and adiposity measures were identified among a representative sample of Australian men and women. Understanding how foods are combined together to form eating occasions will inform the development of targeted nutritional strategies that aim to improve diet quality. However, future research is needed to understand the sociocultural and contextual influences on food choices at eating occasions and to examine food profiles at other eating occasions across the day (e.g. lunch, dinner, and snacks) in relation to health markers.

\section{Abbreviations}

ABS: Australian Bureau of Statistics; ADG: Australian Dietary Guidelines; AUSNUT: Australian Food and Nutrient Database; BMI: Body mass index; Cl: Confidence interval; LVMM: Latent variable mixture modelling; OR: Odds ratio; RGLF: Refined grain or lower fibre; SSB: Sugar-sweetened beverages; WC: Waist circumference; WGHF: Wholegrain or high fibre

\section{Supplementary Information}

The online version contains supplementary material available at https://doi. org/10.1186/s12966-021-01115-w.

Additional file 1. Participant flowchart for inclusion in the analysis of breakfast food profiles and their associations with food intake, participant characteristic and adiposity measures. 
Additional file 2. Food groups at breakfast eating occasions used as input variables for the latent variable mixture modelling.

Additional file $\mathbf{3}$ Reported consumption (\%) of food group intake at the breakfast eating occasion among Australian men who completed the second recall day $(n=2320)$, by latent breakfast profile.

Additional file 4 Reported consumption (\%) of food group intake at the breakfast eating occasions among Australian women who completed the second recall day $(n=2770)$, by latent breakfast profile.

Additional file 5 Energy-adjusted food group intakes at the breakfast eating occasion according to breakfast profile among Australian men breakfast consumers ( $n=3545)$

Additional file 6 Energy-adjusted food group intakes at the breakfast eating occasion according to breakfast profile among Australian women breakfast consumers $(n=4127)$

\section{Acknowledgements}

Not applicable.

\section{Authors' contributions}

RML, CJB and SAM conceived the research. RML analysed the data, drafted the manuscript and takes responsibility for the final manuscript content. All authors contributed to the interpretation of the data, revised the manuscript for important intellectual content and read and approved the final manuscript.

\section{Funding}

RML is supported by a National Heart Foundation Postdoctoral Research Fellowship (ID102109) and National Health and Medical Research Council Emerging Leadership Fellowship L1 (APP1175250). The funders had no role in the data analysis or manuscript preparation.

\section{Availability of data and materials}

Data are available on request from the Australian Bureau of Statistics from https://www.abs.gov.au/websitedbs/D3310114.nsf/home/Microdata\%2 BEntry\%2BPage. The research team does not have the permission to release the data to third parties.

\section{Declarations}

\section{Ethics approval and consent to participate}

The Census and Statistics Act 1905 provides ethics approval for the Australian Bureau of Statistics to conduct the household interview components of health surveys. This study was secondary analysis of nonidentifiable data and an exemption from ethics review was approved by the Deakin University Human Research Ethics Committee ([DUHREC]; application 2018-415).

\section{Consent for publication}

Not applicable.

\section{Competing interests}

The authors declare that they have no competing interests.

\section{Author details}

${ }^{1}$ Institute for Physical Activity and Nutrition (IPAN), School of Exercise and Nutrition Sciences, Deakin University, Geelong, Victoria, Australia.

${ }^{2}$ Epidemiology Program, University of Hawaii Cancer Center, Honolulu, HI, USA.

\section{Received: 13 October 2020 Accepted: 16 March 202}

Published online: 25 March 2021

\section{References}

1. Global Burden of Disease 2017 Diet Collaborators. Health effects of dietary risks in 195 countries, 1990-2017: a systematic analysis for the global burden of disease study 2017. Lancet. 2019;393:1958-72.

2. National Health and Medical Research Council. Australian dietary guidelines. Canberra: NHMRC; 2013.
3. U.S. Department of Health and Human Services and U.S. Department of Agriculture. 2015-2020 dietary guidelines for Americans. 8th ed; 2015. Available from: http://health.gov/dietaryguidelines/2015/

4. Food and Agrigulture Organization of the United Nations. Food-based dietary guidelines. 2019. Available from: http://www.fao.org/nutrition/educa tion/food-dietary-guidelines/en/.

5. Mozaffarian D, Rosenberg I, Uauy R. History of modern nutrition scienceimplications for current research, dietary guidelines, and food policy. BMJ. 2018;361:k2392.

6. Schulze MB, Martinez-Gonzalez MA, Fung TT, Lichtenstein AH, Forouhi NG. Food based dietary patterns and chronic disease prevention. BMJ. 2018;361: k2396.

7. Leech RM, Worsley A, Timperio A, McNaughton SA. Understanding meal patterns: definitions, methodology and impact on nutrient intake and diet quality. Nutr Res Rev. 2015:28:1-21.

8. Pendergast FJ, Leech RM, McNaughton SA. Novel online or mobile methods to assess eating patterns. Curr Nutr Rep. 2017:6:212-27.

9. St-Onge MP, Ard J, Baskin ML, Chiuve SE, Johnson HM, Kris-Etherton P, Meal Timing VK. Frequency: implications for cardiovascular disease prevention: a scientific statement from the American Heart Association. Circulation. 2017; 135:e96-e121.

10. Mozaffarian D, Griffin T, Mande J, Mason JB, Micha R. Topics and comments to be examined in the review of the scientific evidence supporting the development of the 2020-2025 dietary guidelines for Americans, Docket No. FNS-2018-0005-0001. Boston: Tufts University; 2018. Available from: https://nutrition.tufts.edu/sites/default/files/documents/DGAComments-201 8.pdf

11. Dietary Guidelines Advisory Committee. Scientific report of the 2020 dietary guidelines advisory committee: advisory report to the secretary of agriculture and the secretary of health and human services. Washington, DC: U.S. Department of Agriculture, Agricultural Research Service; 2020.

12. Spence C. Breakfast: the most important meal of the day? Int J Gastronomy Food Sci. 2017:8:1-6

13. Williams PG. The benefits of breakfast cereal consumption: a systematic review of the evidence base. Adv Nutr. 2014;5:636S-73S.

14. Priebe MG, McMonagle JR. Effects of ready-to-eat-cereals on key nutritional and health outcomes: a systematic review. PLoS One. 2016;11:e0164931.

15. Quatela A, Callister R, Patterson AJ, McEvoy M, MacDonald-Wicks LK Breakfast cereal consumption and obesity risk amongst the mid-age cohort of the Australian longitudinal study on women's health. Healthcare (Basel). 2017;5.

16. Meiselman HL. Meals in science and practice : interdisciplinary research and business applications. Boca Raton: CRC Press; Woodhead Publishing Ltd; 2009

17. Hearty AP, Gibney MJ. Analysis of meal patterns with the use of supervised data mining techniques--artificial neural networks and decision trees. Am J Clin Nutr. 2008:88:1632-42

18. Woolhead C, Gibney MJ, Walsh MC, Brennan L, Gibney ER. A generic coding approach for the examination of meal patterns. Am J Clin Nutr. 2015;102: 316-23

19. Schwedhelm C, Knuppel S, Schwingshackl L, Boeing H, labal K. Meal and habitual dietary networks identified through Semiparametric Gaussian copula graphical models in a German adult population. PLoS One. 2018;13: e0202936.

20. McNaughton SA. Dietary patterns and diet quality: approaches to assessing complex exposures in nutrition. Australas Epidemiol. 2010;17:35-7.

21. Muthen B, Muthen LK. Integrating person-centered and variable-centered analyses: growth mixture modeling with latent trajectory classes. Alcohol Clin Exp Res. 2000;24:882-91.

22. Everitt BS, Landau S, Leese M, Stahl D. Cluster analysis. 5th ed. West Sussex: Wiley; 2011

23. Leech RM, McNaughton SA, Timperio A. The clustering of diet, physical activity and sedentary behavior in children and adolescents: a review. Int J Behav Nutr Phys Act. 2014;11:4.

24. Newby PK, Muller D, Tucker KL. Associations of empirically derived eating patterns with plasma lipid biomarkers: a comparison of factor and cluster analysis methods. Am J Clin Nutr. 2004;80:759-67.

25. Lobo AS, de Assis MAA, Leal DB, Borgatto AF, Vieira FK, Di Pietro PF, Kupek E. Empirically derived dietary patterns through latent profile analysis among Brazilian children and adolescents from southern Brazil, 2013-2015. PLoS One. 2019;14:e0210425. 
26. Leech RM, Worsley A, Timperio A, McNaughton SA. Temporal eating patterns: a latent class analysis approach. Int J Behav Nutr Phys Act. 2017;14: 3

27. Khanna N, Eicher-Miller HA, Boushey CJ, Gelfand SB, Delp EJ. Temporal dietary patterns using kernel k-means clustering. Ism. 2011;2011:375-80.

28. Kent $\mathrm{P}$, Jensen RK. Kongsted a. a comparison of three clustering methods for finding subgroups in MRI, SMS or clinical data: SPSS TwoStep cluster analysis, latent gold and SNOB. BMC Med Res Methodol. 2014;14:113.

29. Australian Bureau of Statistics. Australian health survey: users' guide, $2011-$ 13. Cat. no. 4363.0.55.001. Canberra: ABS; 2013.

30. Blanton CA, Moshfegh AJ, Baer DJ, Kretsch MJ. The USDA automated multiple-pass method accurately estimates group total energy and nutrient intake. J Nutr. 2006;136:2594-9.

31. Moshfegh AJ, Rhodes DG, Baer DJ, Murayi T, Clemens JC, Rumpler WV, Paul DR, Sebastian RS, Kuczynski KJ, Ingwersen LA, et al. The US Department of Agriculture Automated Multiple-Pass Method reduces bias in the collection of energy intakes. Am J Clin Nutr. 2008:88:324-32.

32. Leech RM, Worsley A, Timperio A, McNaughton SA. Characterizing eating patterns: a comparison of eating occasion definitions. Am J Clin Nutr. 2015: 102:1229-37.

33. Deshmukh-Taskar P, Nicklas TA, Radcliffe JD, O'Neil CE, Liu Y. The relationship of breakfast skipping and type of breakfast consumed with overweight/obesity, abdominal obesity, other cardiometabolic risk factors and the metabolic syndrome in young adults. The National Health and Nutrition Examination Survey (NHANES): 1999-2006. Public Health Nutr. 2013;16:2073-82.

34. Vieux F, Maillot M, C DR, Drewnowski A. Designing optimal breakfast for the United States using linear programming and the NHANES 2011-2014 database: a study from the international breakfast research initiative (IBRI). Nutrients. 2019;11.

35. O'Neil CE, Nicklas TA, Fulgoni VL 3rd. Nutrient intake, diet quality, and weight/adiposity parameters in breakfast patterns compared with no breakfast in adults: National Health and Nutrition Examination Survey 20012008. J Acad Nutr Diet. 2014;114:S27-43.

36. Food Standards Australia New Zealand. Assessing the 2011-13 AHS against the Australian dietary guidelines. 2017. Available from: http://www.foodsta ndards.gov.au/science/monitoringnutrients/australianhealthsurveyandaustra liandietaryguidelines/Pages/default.aspx.

37. Food Standards Australia New Zealand. AUSNUT 2011-13: Australian food, supplement and nutrient database. 2013. Available from: http://www. foodstandards.gov.au/science/monitoringnutrients/ausnut/Pages/about.aspx.

38. Australian Bureau of Statistics. Australian health survey User's guide, 201113 - discretionary foods. Cat no: 4363.0.55.001. 2013. Available from: http:// www.abs.gov.au/ausstats/abs@.nsf/Lookup/4363.0.55.001Chapter65062 011-13.

39. Willett W. Nutritional epidemiology. 3rd ed. New York: Oxford University Press; 2013.

40. Willett WC, Howe GR, Kushi LH. Adjustment for total energy intake in epidemiologic studies. Am J Clin Nutr. 1997;65:1220S-8S discussion 1229S12315.

41. Australian Institute of Health and Welfare. The active Australia survey: a guide and manual for implementation, analysis and reporting. Cat. no. CVD 22. Canberra: AlHW; 2003.

42. Wickrama KAS, Lee TK, O'Neal CW, Lorenz FO. Higher-order growth curves and mixture modeling with Mplus: a practical guide. 1st ed. New York, NY: Routledge; 2016

43. Muthen LK, Muthen BO. Mplus user's guide. 8th ed. Los Angeles: Muthen \& Muthen; 1998-2017.

44. Chung SJ, Lee Y, Lee S, Choi K. Breakfast skipping and breakfast type are associated with daily nutrient intakes and metabolic syndrome in Korean adults. Nutr Res Pract. 2015;9:288-95.

45. Ma G. Food, eating behavior, and culture in Chinese society. J Ethnic Foods. 2015;2:195-9.

46. Jastran MM, Bisogni CA, Sobal J, Blake C, Devine CM. Eating routines. Embedded, value based, modifiable, and reflective. Appetite. 2009:52:12736.

47. Monsivais P, Aggarwal A, Drewnowski A. Time spent on home food preparation and indicators of healthy eating. Am J Prev Med. 2014;47:796802.

48. Smith KJ, McNaughton SA, Gall SL, Blizzard L, Dwyer T, Vennl AJ. Involvement of young Australian adults in meal preparation: crosssectional associations with sociodemographic factors and diet quality. J Am Diet Assoc. 2010:110:1363-7.

49. Barr Sl, DiFrancesco L, Fulgoni VL 3rd. Consumption of breakfast and the type of breakfast consumed are positively associated with nutrient intakes and adequacy of Canadian adults. J Nutr. 2013;143:86-92.

50. Siega-Riz AM, Popkin BM, Carson T. Differences in food patterns at breakfast by sociodemographic characteristics among a nationally representative sample of adults in the United States. Prev Med. 2000;30:415-24.

51. Gibney MJ, Barr SI, Bellisle F, Drewnowski A, Fagt S, Livingstone B, Masset G, Varela Moreiras G, Moreno LA, Smith J, et al. Breakfast in human nutrition: the international breakfast research initiative. Nutrients. 2018:10.

52. Chowdhury EA, Richardson JD, Holman GD, Tsintzas K, Thompson D, Betts $J A$. The causal role of breakfast in energy balance and health: a randomized controlled trial in obese adults. Am J Clin Nutr. 2016.

53. Keski-Rahkonen A, Kaprio J, Rissanen A, Virkkunen M, Rose RJ. Breakfast skipping and health-compromising behaviors in adolescents and adults. Eur J Clin Nutr. 2003;57:842-53.

54. Deshmukh-Taskar PR, Radcliffe JD, Liu Y, Nicklas TA. Do breakfast skipping and breakfast type affect energy intake, nutrient intake, nutrient adequacy, and diet quality in young adults? NHANES 1999-2002. J Am Coll Nutr. 2010; 29:407-18.

55. Dashti HS, Merino J, Lane JM, Song Y, Smith CE, Tanaka T, McKeown NM, Tucker C, Sun D, Bartz TM, et al. Genome-wide association study of breakfast skipping links clock regulation with food timing. Am J Clin Nutr. 2019;110:473-84.

56. Subar AF, Freedman LS, Tooze JA, Kirkpatrick SI, Boushey C, Neuhouser ML, Thompson FE, Potischman N, Guenther PM, Tarasuk V, et al. Addressing current criticism regarding the value of self-report dietary data. J Nutr. 2015; 145:2639-45.

57. Jackson KA, Byrne NM, Magarey AM, Hills AP. Minimizing random error in dietary intakes assessed by $24-h$ recall, in overweight and obese adults. Eur J Clin Nutr. 2008;62:537-43.

58. McCann SE, Marshall JR, Brasure JR, Graham S, Freudenheim JL. Analysis of patterns of food intake in nutritional epidemiology: food classification in principal components analysis and the subsequent impact on estimates for endometrial cancer. Public Health Nutr. 2001;4:989-97.

59. Benisi-Kohansal S, Saneei P, Salehi-Marzijarani M, Larijani B, Esmaillzadeh A. Whole-grain intake and mortality from all causes, cardiovascular disease, and cancer: a systematic review and dose-response meta-analysis of prospective cohort studies. Adv Nutr. 2016;7:1052-65.

60. World Cancer Research Fund/Amercian Institute for Cancer Research. Diet, nutrition, physical activity and cancer: a global perspective. Continuous update project expert report: WCRF; 2018. Available at dietandcancerreport. org

61. Hruby A, Sahni S, Bolster D, Jacques PF. Protein intake and functional integrity in aging: the Framingham heart study offspring. J Gerontol A. 2018;75:123-30.

62. Buttriss JL, Briend A, Darmon N, Ferguson EL, Maillot M, Lluch A. Diet modelling: how it can inform the development of dietary recommendations and public health policy. 2014:39:115-25.

63. Davis KA, Esslinger K, Elvidge Munene L-A, St-Pierre S. International approaches to developing healthy eating patterns for national dietary guidelines. Nutr Rev. 2019;77:388-403.

\section{Publisher's Note}

Springer Nature remains neutral with regard to jurisdictional claims in published maps and institutional affiliations.

Ready to submit your research? Choose BMC and benefit from:

- fast, convenient online submission

- thorough peer review by experienced researchers in your field

- rapid publication on acceptance

- support for research data, including large and complex data types

- gold Open Access which fosters wider collaboration and increased citations

- maximum visibility for your research: over $100 \mathrm{M}$ website views per year

At $\mathrm{BMC}$, research is always in progress.

Learn more biomedcentral.com/submissions 